measure does not compare response rate during the CS with response rate in its absence, the incentive effect reported may have reflected differential recovery rate of base-line responding rather than differences in CS-elicited suppression. The present study suggests that sucrose concentration affects the former but not the latter.

Another possible explanation for the discrepancy between the Vogel and Spear findings and ours is as follows: It may be that when base-line rates are just recovering from the effects of shock, those maintained by low incentives are particularly fragile. But once the base lines have approached their normal levels, they are equally robust. Vogel and Spear gave suppression tests after their Ss had completed only 100 licks. Our tests were given after a much longer period of recovery. In Ayres's study, too, suppression tests were widely spaced apart, allowing response rates to recover in between. This hypothesis, of course, is completely ad hoc and does not follow from any theory we know of; yet it does describe what happened in the three studies, and it does make sense of the present finding that incentives appeared to affect suppression to static apparatus cues but not suppression to a dynamic CS.

Regardless of what the reason for the discrepancy is, one thing seems apparent:
In the present study and in that of Ayres (1968), there was a lack of covariation between response strength as indexed by barpress rate and by resistance to CS-elicited suppression. This finding, along with that described earlier by Blackman (1968), seems to reaffirm Logan's position (Logan, 1956), that fast behaviors are not necessarily strong behaviors; they're just different.

\section{REFERENCES}

AYRES, J. J. B. Differentially conditioned suppression as a function of shock intensity and incentive. Journal of Comparative \& Physiological Psychology, 1968, 66, 208-210.

BLACKMAN, D. Response rate, reinforcement frequency, and conditioned suppression. Journal of the Experimental Analysis of Behavior, 1968, 11, 503-516.

J A M ES, J. P., \& MOSTOWAY, W. W. Conditioned suppression of licking as a function of shock intensity. Psychonomic Science, 1968, 13, 161-162.

LOGAN, F. A. A micromolar approach to behavior theory. Psychological Review, 1956. 63, 63-73.

MORGAN, J. J. B. The measurement of instincts. Psychological Bulletin, 1923, 20, 94.

QUINSEY, V. L., \& AYRES, J, J. B. The effect of CS-induced fear on a partially extinguished CER. Psychonomic Science, 1969. 14, 242-244.

VOGEL, J. R., \& SPEAR, N. F. Interaction of reward magnitude and conditioned fear on the consummatory response. Psychonomic Science, 1966, 5, 263-264.

\title{
The classically conditioned nictitating membrane response: The CS-US interval function with one trial per day
}

\author{
CHARLES F. LEVINTHAL and JAMES D. PAPSDORF \\ University of Michigan, Ann Arbor, Mich. 48104
}

Acquisition rates for the classically conditioned nictitating membrane response of the rabbit were determined, using one paired presentation of tone and shock per day for 12 days, in Ss trained at a CS-US interval of either 250 or $1,250 \mathrm{msec}$. Although both groups displayed substantial conditioning, the 1,250 -msec group was significantly superior to the 250-msec group, in marked contrast to the usual findings of experiments dealing with the CS-US interval parameter. Results are interpreted primarily in terms of the role of the orienting response in $\mathrm{CR}$ acquisition.

The function of the CS-US interval (interstimulus interval or ISI) in the rate of acquisition of a classically conditioned response is one of the most thoroughly investigated variables in the conditioning literature. One generally finds a concave down function of acquisition rate to ISI, peaking for the nictitating membrane response (NMR) of the rabbit around $250 \mathrm{msec}$ (Smith, Coleman, \& Gormezano, 1969; Schneiderman \& Gormezano, 1964).

The procedure for obtaining the ISI function has involved, with a few exceptions (e.g., Frey \& Ross, 1968), either (1) a single conditioning session where the intertrial interval (ITI) was shorter than $120 \mathrm{sec}$ or (2) multiple daily sessions where the within-session ITI was shorter than $120 \mathrm{sec}$ and the between-session ITI approached $24 \mathrm{~h}$.

In view of the scarcity of ISI studies involving very long ITIs with the single-session procedure and the inherent ambiguity of the ITI variable in multiple sessions, it was considered worthwhile to examine the rate of response acquisition and, in particular, the ISI function when the ITI was 24 h, i.e., when there was only one trial per day. Earlier pilot work had suggested that as trials per day decreased from 15 downward, the acquisition rate observed over training days was not greatly altered, and the ISI function became substantially flattened.

\section{SUBJECTS}

The Ss were 24 male New Zealand rabbits, 90-120 days old, obtained from Johnsons Rabbitry, Coldwater, Michigan. Throughout the experiment, the Ss were maintained on ad lib food and water.

\section{PROCEDURE}

Forty-eight hours prior to the first experimental session, a small nylon loop was sutured into $\mathrm{S}$ 's right nictitating membrane. On the following day each $\mathrm{S}$ was placed in a Plexiglas restraining box for a $10-\mathrm{min}$ habituation period. During this period, as in the experimental sessions, tailor hooks which served to retract the eyelids and deliver the shock US were fastened by adjustable Velcro straps to the inferior and superior lids of the right eye. Movements of the nictitating membrane across the eye were monitored by a small photoelectric transducer, mounted on the S's head by means of a muzzle-like assembly and mechanically coupled to the loop in the membrane. Signals for the transducer were amplified and recorded by a Beckman Type $\mathrm{R}$ dynograph.

On each of 12 subsequert days Ss received one paired CS.US presentation. The CS, a $1,000-\mathrm{Hz}$ tone at $93 \mathrm{~dB} \mathrm{SPL}$, was presented for either $350 \mathrm{msec}$ or $1,350 \mathrm{msec}$. The US was a $3-\mathrm{mA} 60-\mathrm{Hz}$ shock delivered across the eyelids and

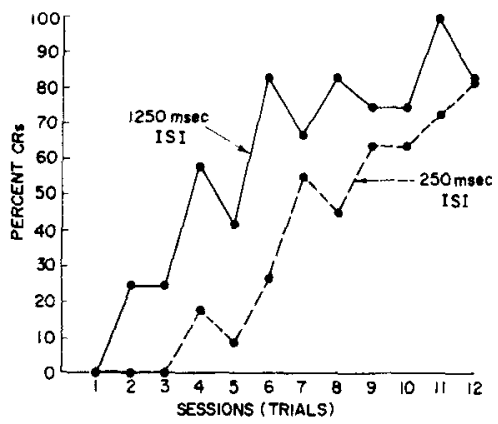

Fig. 1. Mean percentage of CRs of $S s$ in either the $250-\mathrm{msec}$ or the $1,250-\mathrm{msec}$ condition. 
Table 1

Median Response Latency Scores (in Msec) of Ss Over Blocks of Three Sessions

\begin{tabular}{rcccc}
\hline & \multicolumn{4}{c}{ Sessions (Trials) } \\
\cline { 3 - 5 } Condition & $1-3$ & $4-6$ & $7-9$ & $10-12$ \\
\hline $250 \mathrm{msec}$ & & 173 & 184 & 148 \\
$1250 \mathrm{msec}$ & 750 & 620 & 510 & 356 \\
\hline
\end{tabular}

overlapping the last $100 \mathrm{msec}$ of $\mathrm{CS}$ presentation. After the single daily trial, all Ss remained in the experimental enclosure for $10 \mathrm{~min}$, following which they were returned to their home cages.

The 24 Ss were randomly assigned to two groups having ISI parameter values of either 250 or $1,250 \mathrm{msec}$. One $250-\mathrm{msec} S$ died during the experiment, leaving a final $\mathrm{N}$ of 11 for that group.

\section{RESULTS}

The mean percentage of CRs for the two groups on each of the 12 conditioning-session trials is presented in Fig. 1.

On Trials 1-12, the 1,250-msec-group Ss were superior in performance to those of the 250-msec group. The Mann-Whitney U-test yielded a significant difference between the two groups with respect to the total number of $\mathrm{CRs}$ for each $\mathrm{S}$ over 12 trials $(\mathrm{U}=30, \mathrm{p}<.025$, one-tailed $)$.

Table 1 lists the median $C R$ latencies across blocks of three sessions for the two groups. Across the session blocks, median latencies shifted toward CS onset.

\section{DISCUSSION}

The substantial conditioning achieved by the 1,250-msec group, asymptotic around $80 \%$ by the sixth single-trial session, compares favorably with performance of normal animals at comparable ISI values ( $1,000-1,250 \mathrm{msec})$ with five trials per day, ITI $=60 \mathrm{sec}$ (Levinthal \& Papsdorf, 1970), and 15 trials per day, ITI $=60 \mathrm{sec}$ (Cholewiak, Hammond, Seigler, \& Papsdorf, 1968), when performance is compared over conditioning sessions. General conclusions from comparisons across studies, however, are admittedly premature, owing to procedural differences, the most prominent of which is the greater CS intensity in the present study. Since, in general, the increase in CS intensity enhances conditioning rates (Gormezano \& Moore, 1969), a final conclusion regarding the similarity of acquisition rate for one-trial-per-day Ss to those with multiple-trials sessions is not yet warranted. Although Hupka, Massaro, \& Moore (1968) have found that acquisition rates over sessions increase as trials per day are increased from 15 to 90 , the equivalent comparisons for from 1 to 15 trials, within a single study, remain to be specified.

Although formal sensitization controls were not run in the present study, it can be argued that such an alternative explanation of the results is unlikely. First, with the 24-h ITI, US-induced sensitization would be minimal at time of CS onset. Second, the median latency measures of Table 1 are not unlike those described by others employing multiple-trial sessions (Schneiderman \& Gormezano, 1964; Smith, 1968).

The most interesting result is the obvious superiority of the 1,250 -msec ISI group. Since traditional models of the ISI function in classical conditioning appear inadequate in handling this reversal, additional hypotheses have to be invoked. One interpretation of the results postulates the existence of a CS-elicited orienting response (OR) occurring early in the ISI which can be antagonistic to the performance of the CR during the first few milliseconds subsequent to $\mathrm{CS}$ onset. Evidence supporting the interaction of the $O R$ and $C R$ in certain response systems has been discussed in a recent review by Lynn (1966). A possible peripheral component of the OR can, in fact, be observed early in conditioning when, shortly following CS onset, the nictitating membrane moves farther into the nasal canthus, opposite in direction to the normally observed unconditioned nictitating membrane response to shock.

Most frequently used conditioning procedures would serve to habituate the OR, e.g., short ITIs, multiple trials per day, etc. However, with one trial per day, the OR would not habituate and would continue to compete with the execution of the $C R$, if $C R$ latencies coincided with the presence of the $O R$. Consequently, interference from a nonhabituated $O R$ would more strongly affect short ISI groups (250 msec). Ss in longer ISI groups would be less affected, since at the normal time of CR occurrence the OR would have diminished in strength. As in the original conception by Pavlov (1927), the OR itself would provide the best necessary attentional assistance to optimal encoding of the CS-US contingency. In the present context, the short ISI groups would encode the contingency most effectively since the OR would span the entire interval. Nonoptimality of ISI values shorter than $200-250 \mathrm{msec}$ may be a result of perceptual difficulties regarding the ordinal nature of the CS-US event, although other explanations of the lower range of the ISI function have been proposed (Gormezano, 1969). Thus, with procedures that provide for the habituation of the OR, the customary ISI function is predicted.

The above theory interprets the ISI reversal obtained with one trial per day as chiefly a performance effect, with nonhabituated ORs as potential competitors of $\mathrm{CR}$ execution. One alternative to this position is that the reversal is due to ISI differences in the rate of associative development. Specifically, consolidation rates as a function of ISI may differ in terms of the existing arousal level. With one shock per session, the arousal level may be such as to facilitate consolidative processes more for the long ISI than for the short ISI condition. As both the orienting response and arousal level hypotheses require further empirical investigation, including the development of independent assessment procedures for processes hypothesized by these theories, further speculation along these lines is not presently warranted. Nevertheless, the results of this study do require a considerable revision of current theories of the ISI function in CR acquisition.

\section{REFERENCES}

CHOLEWIAK, R. W., HAMMOND, R. SEIGLER, I. C., \& PAPSDORF, J. D. Effects of strychnine sulphate on classically conditioned nictitating membrane responses of rabbits. Journal of Comparative \& Physiological Psychology, 1968, 66, 77-81.

FREY, P. W., \& ROSS, L. E. Classical conditioning of the rabbit eyelid response as a function of the interstimulus interval. Journal of Comparative \& Physiological Psychology, $1968,65,246-250$.

GORMEZANO, I. The stimulus trace hypothesis and investigations of defense and reward conditioning in the rabbit. Paper presented at the Conference on Classical Conditioning at McMaster University, May 1969.

GORMEZANO, I., \& MOORE, J. W. Classical conditioning. In M. H. Marx (Ed.), Learning Processes. Toronto: MacMillan, 1969. Pp. 119-203.

HUPKA, R. B., MASSARO, D. W., \& MOORE, J. W. Yoked comparisons of instrumental avoidance and classical conditioning of the rabbit nictitating membrane response as a function of interstimulus interval and number of trials per day. Psychonomic Science, 1968, $12,93-94$.

LEVINTHAL, C. F., \& PAPSDORF, J, D. Experimental variables in the effects of post-session injections of strychnine sulphate on a classically conditioned response. Psychopharmacologia (Berlin), 1970, 17, 100-104.

LYNN, R. Attention, arousal, and the orientation reaction. Oxford: Pergamon, 1966.

PAVLOV, I. Conditioned reflexes. (Translated by G. V. Anrep) London: Oxford University Press, 1927.

SCHNEIDERMAN, N., \& GORMEZANO, I. Conditioning of the nictitating membrane of the rabbit as a function of CS-US interval. Journal of Comparative \& Physiological Psychology, 1964, 57, 188-195.

SMITH, M. C. CS-US interval and US intensity in classical conditioning of the rabbit's nictitating membrane response. Journal of Comparative \& Physiological Psychology, 1968, 66, 679-687. SMITH, M. C., COLEMAN, S. R., \& GORMEZANO, I. Classical conditioning of the rabbit's nictitating membrane response at backward simultaneous and forward CS-US intervals. Journal of Comparative \& Physiological Psychology, 1969, 69, 226-231. 